\title{
Material characterisation to understand various modes of corrosion failures in large military vehicles of historical importance
}

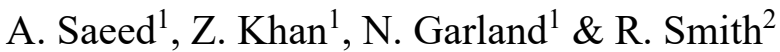 \\ ${ }^{1}$ Bournemouth University, UK \\ ${ }^{2}$ The Tank Museum, Bovington, UK
}

\begin{abstract}
Large military vehicles within museum collections are stored in two distinct environments, controlled and uncontrolled, with an intermittent transitional mode where vehicles travel between the two. Variable environmental conditions combined with operational factors pose significant risks to the reliability, durability and longevity of these vehicles. Although there are methods for retarding or decelerating aspects of failure, to maintain the integrity and originality of these vehicles as artefacts, a sustainable methodology for conserving them should be developed. Corrosion is one of the significant contributors to the structural damage and material aging of historical military vehicles; therefore, an experimental study was conducted to understand the prevailing mechanisms of failures due to corrosion with the various types occurring in these vehicles identified. This paper describes the various modes of corrosion in historic vehicles while X-ray fluorescence and ultrasonic scanning corrosion mapping techniques characterise corrosion inhibiting materials and subsequent material loss. Understanding material profiles and their link to environmental exposure during use and non use of these vehicles will lead to a sustainable methodology for their conservation.
\end{abstract}

Keywords: sustainable, military, vehicle, corrosion, materials, conservation.

\section{Introduction}

The structural and functional deterioration of the large metal structures due to their environmental exposure and the operating conditions are responsible for their structural aging [1]. Aging mechanisms in large metal structures such as bridges, aircrafts, vehicles etc is recognised as a growing problem [2]. Aging mechanisms 
such as corrosion, surface and sub surface cracks, wear due to interacting surfaces and undesired stresses are leading to mechanical failures, higher maintenance costs and compromise structural integrity. Corrosion has been identified as one of the major contributor to the aging mechanisms; it affects all metal structures by deteriorating the material's properties [3].

This research focuses upon the corrosion damage within large historic vehicles in the museum environment. Corrosion is indiscriminate in affecting metal structures and museum artefacts are no exception. The military vehicles from World Wars I and II were designed and manufactured according to the automotive technologies in place at those times [4] with only a limited life-expectancy, however their participation in the war and the subsequent historic significance means it is important to devise sustainable methodologies for long-term preservation. Continuous corrosion problems within large historic military vehicles in the museum environment are leading to concerns about their longevity, in particular where failures in protective measures are also identified [5]. For the purpose of sustainable methods, it is important to understand the various corrosion modes, material characterisation and the material loss profile due to corrosion.

For this research, military vehicles were inspected for visual signs of corrosion and novel methods such as X-ray fluorescence for elemental identification and ultrasonic scanning for material loss were conducted. Visual inspection identified different modes of corrosion depending on their exposure to extreme environments during the war, operating conditions at the time of their service life, types of materials used and their current working or non-working environments.

X-Ray fluorescence method found Fe, the main constituent; other elements such as W, Mo and Mn were also identified. Ultrasonic methods found severe material loss due to corrosion in the selected samples.

\section{Experimental methodologies}

The following methods are used in the research. Only the most common and reoccurring types of corrosion which were found on a larger scale in the vehicles are presented here.

\subsection{Visual inspection}

Visual inspection was completed on more than 20 large military vehicles from the World War I, II and post war eras. The investigation found one or more forms of corrosion in the same vehicles. Some widespread and most occurring modes of corrosion are described from four military tanks in Table 1.

\subsection{X-ray fluorescence}

X-ray fluorescence (XRF) was conducted on Sherman M4A1 for elemental identification. The test sample was bombarded by an intense X-ray beam resulting in the emission of fluorescent $\mathrm{x}$-rays from the test object. The emitted fluorescent $x$-rays are then detected by XRF analyser [6] which identifies the elements by measuring the energies of the emitted fluorescent $\mathrm{x}$-rays and counting the number of rays in each energy spectrum $[6,7]$. 
Table 1: Military tanks presented in this research.

\begin{tabular}{|c|l|l|l|l|l|}
\hline No & Vehicle & Environment & Manufacture & Country of origin & Era \\
\hline 1 & Mark II & Controlled & 1917 & United Kingdom & WW1 \\
\hline 2 & Sherman* & Uncontrolled & $1940-1941$ & United States & WW2 \\
\hline 3 & King Tiger & Controlled & 1943 & Germany & WW2 \\
\hline 4 & Centurion & Uncontrolled & 1945 & United Kingdom & Post war \\
\hline 5 & Scorpion & Uncontrolled & 1973 & United Kingdom & Post war \\
\hline
\end{tabular}

$\mathrm{XRF}$ and ultrasonic scanning is conducted on Sherman.

\subsection{Ultrasonic scanning}

Ultrasonic scanning uses pulse waves from 0.10 to $15.0 \mathrm{MHz}$ frequencies range to measure material loss and other dimensional anomalies in the test objects [8]. This research work presents ultrasonic scanning using the pulse echo method whereby pulses are transmitted and received back on the same side of the test object to detect and characterise defects.

\section{Results}

\subsection{Uniform corrosion}

With uniform corrosion, a direct chemical attack affects the surface of the metal and then spreads out evenly across the entire surface; the results are not usually fatal and it is not classified as one of the severe forms [9]. Fig. 1 of the King Tiger's flywheel shows uniform corrosion spreading across the surface. Uniform corrosion was also found in Tog II and FT 17 on considerably larger surface areas. Uniform corrosion, if left to continue, could lead to general thinning of the surface and may transform into another form of corrosion [10].

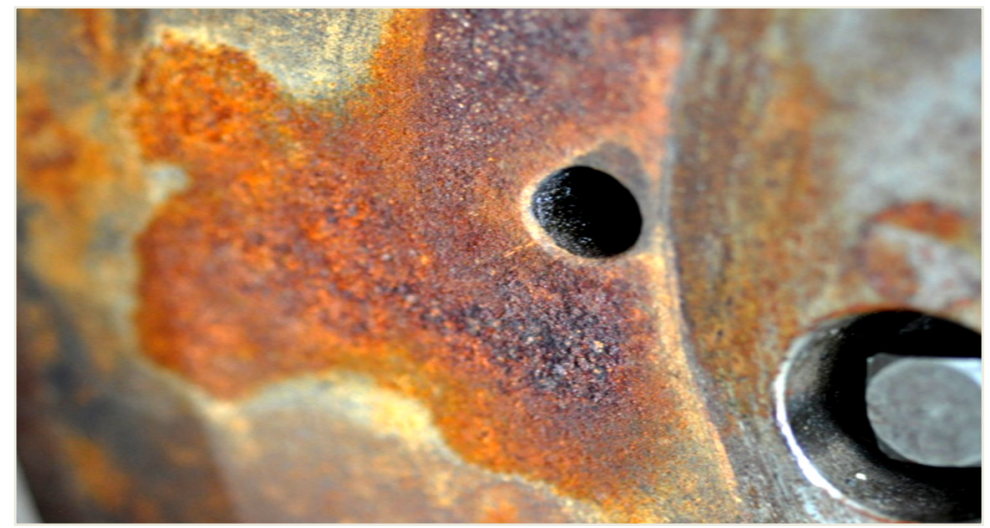

Figure 1: King tiger flywheel. 


\subsection{Fretting corrosion}

Fretting corrosion occurs at the interface of the interacting surfaces which are subject to relative motions. The King Tiger planetary gears (Fig. 2) are a classic example of this form. Interacting mechanical wear leads to the removal of material particles, followed by the oxidation of the material debris and the newly exposed surface [11]. The oxidised debris would act as an abrasive media leading to further wear and fatigue failures could occur $[9,12]$.

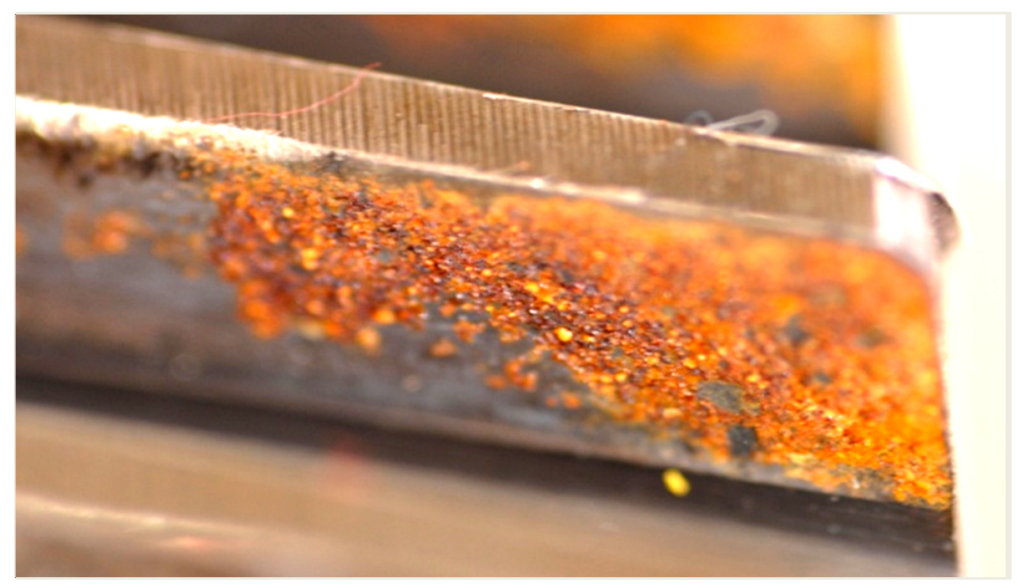

Figure 2: King tiger planetary gears.

\subsection{Stress corrosion cracking}

Stress corrosion cracking is considered one of the severe types of corrosion; it could cause a partial or complete failure of a structure especially in the presence of dynamic or static loading and initiation of a stress corrosion crack [13]. The Mark-II Tank glacis plate in Fig. 3 shows stress corrosion cracking where a crack is initiated and penetrating through the surface with no significant material loss on the surface. Stress corrosion is difficult to detect, hard to predict and unexpected failure can occur $[13,14]$.

\subsection{Galvanic corrosion}

Galvanic corrosion is the electrochemical reaction between two dissimilar metals in the presence of electron conductive path and the preferential corrosion of one metal more than the other $[15,16]$. This mode of corrosion was identified in the Scorpion, see Fig. 4. The presence of moisture among the bolt, washer and the armoured skirt has caused this type of corrosion. 


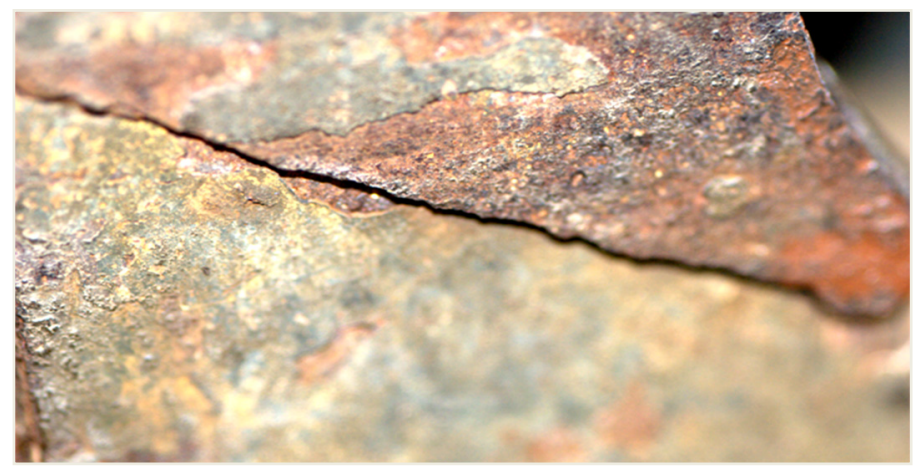

Figure 3: Mark II glacis plate.

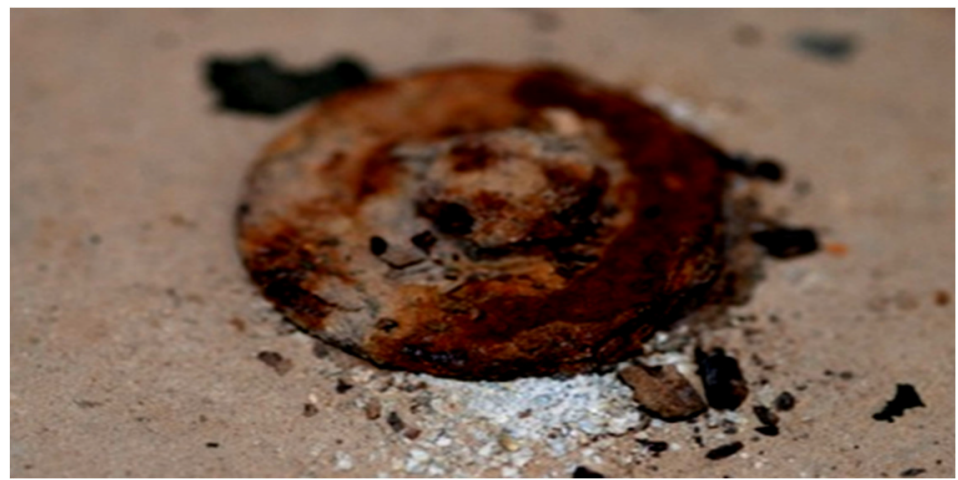

Figure 4: Galvanic corrosion in Scorpion.

\subsection{Pitting corrosion}

Centurion in Fig. 5 shows signs of pitting corrosion. In this case, the corrosion is confined to a small point with resulting cavities in the metal. The localised phenomenon of corrosion creates holes in the metal and then penetrates inwards, deteriorating the metal from the inside. The corrosion products cover the pit and create a small hole with no significant material loss on the surface leading to a catastrophic malfunction; it is one of the severe forms of corrosion, which is very difficult to detect and hard to predict the result $[14,17,18]$.

\subsection{X-ray Fluorescence of the Sherman M4A1}

X-Ray fluoresce (XRF) was conducted on three points A, B, C on corroded, E, F, and $G$ on sand blasted surfaces and point $D$ on the cross section of the sample, see Fig. 6. Table 2 shows the results from points A, B and C. On averages, Fe at $92.07 \%$ is the highest, second highest is the $\mathrm{Si}$ at $5.39 \%$, Mn at $0.91 \%$ was the third highest and the lowest was $\mathrm{Cu}$ with a trace of $0.04 \%$. 


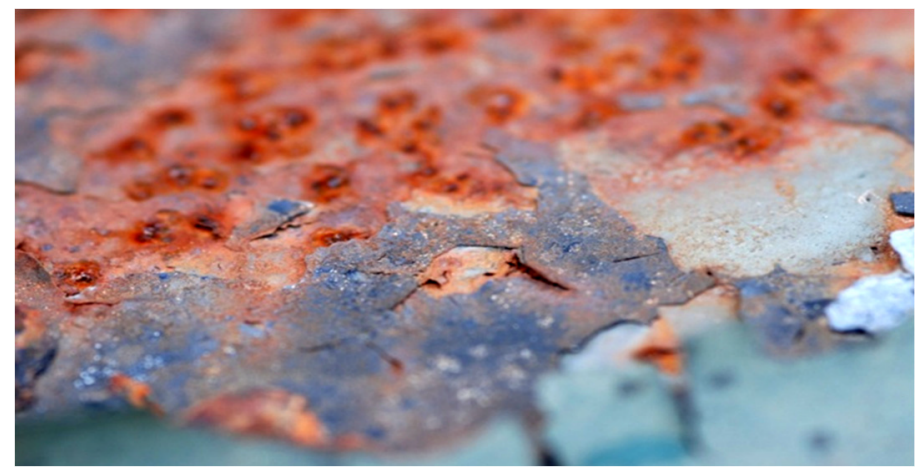

Figure 5: Pitting in Centurion.

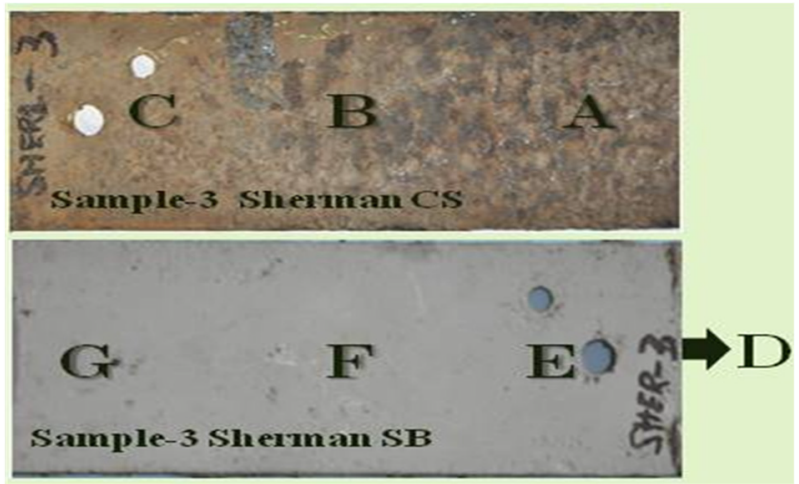

Figure 6: XRF points on Sherman.

Fig. 7 shows the graphical representation of the XRF conducted at point D where $\mathrm{Fe}$ at $98.30 \%$ is the highest, second highest is $\mathrm{Si}$ at $0.65 \%, \mathrm{Mn}$ at $0.63 \%$ the third highest and no traces of Ti, V, Co and Mo were identified.

XRF conducted at points $\mathrm{E}, \mathrm{F}$ and $\mathrm{G}$ on the sandblasted surface shown on averages $\mathrm{Fe}$ at $98.12 \%$ the highest, $\mathrm{Mn}$ at $0.66 \%$ second highest, Si at $0.59 \%$ the third highest while $\mathrm{W}$ at $0.02 \%$ the lowest and no traces of Co or V were identified. Fig. 8 shows the graphical representation of the XRF analysis at point $\mathrm{G}$.

\subsection{Pulse echo ultrasonic scanning}

Pulse Echo scanning was conducted on the Sherman M4A1 with a probe of 4.00 MHz twin crystal and $10.00 \mathrm{~mm}$ diameter using $0.25 \mathrm{MHz} \mathrm{Hi}$ pass filter and $10.00 \mathrm{MHz}$ low pass filter frequencies with a probe delay of $7.630 \mu \mathrm{S}$. Compression waves with a velocity of $5903.00 \mathrm{~m} / \mathrm{s}$ are used to scan a total area of $174.00 \mathrm{~mm}$ length with 6.040 pulses $/ \mathrm{mm}$ and $68.00 \mathrm{~mm}$ width with $3.580 \mathrm{pulses} / \mathrm{mm}$ mapping material loss every $2.00 \mathrm{~mm}$ on the sample. 
Table 2: XRF of the corroded surface of M4A1.

\begin{tabular}{|c|c|c|c|c|}
\hline \multicolumn{5}{|c|}{ Vehicle Type: Sherman } \\
\hline \multicolumn{3}{|c|}{ Sample 1} & \multicolumn{2}{|c|}{ Surface: Corroded } \\
\hline \multicolumn{3}{|c|}{ Time duration: 30 seconds } & \multicolumn{2}{|c|}{$\begin{array}{l}\text { MQ for points: } A=5.70 \quad B=4.50 \\
C C=4.60\end{array}$} \\
\hline \multicolumn{2}{|c|}{ Material Standard } & 06 American & 06 American & 06 American \\
\hline \multicolumn{2}{|c|}{ Constituents \% } & A-Reading 254 & B-Reading 255 & C-Reading 256 \\
\hline 1 & $\mathrm{Si}$ & 4.89 & 5.92 & 5.38 \\
\hline 2 & $\mathrm{P}$ & 0.46 & 0.54 & 0.85 \\
\hline 3 & $\mathrm{Ti}$ & 0.19 & 0.19 & 0.2 \\
\hline 4 & V & 0.05 & 0.05 & 0.05 \\
\hline 5 & $\mathrm{Cr}$ & 0.11 & 0.08 & 0.09 \\
\hline 6 & $\mathrm{Mn}$ & 0.86 & 1.11 & 0.78 \\
\hline 7 & $\mathrm{Fe}$ & 92.68 & 91.48 & 92.05 \\
\hline 8 & Co & 0.21 & 0.22 & 0.12 \\
\hline 9 & $\mathrm{Ni}$ & 0.06 & 0.08 & 0.1 \\
\hline 10 & $\mathrm{Cu}$ & 0.05 & 0.03 & 0.04 \\
\hline 11 & Mo & 0.05 & 0.06 & 0.06 \\
\hline 12 & W & 0.33 & 0.2 & 0.12 \\
\hline
\end{tabular}

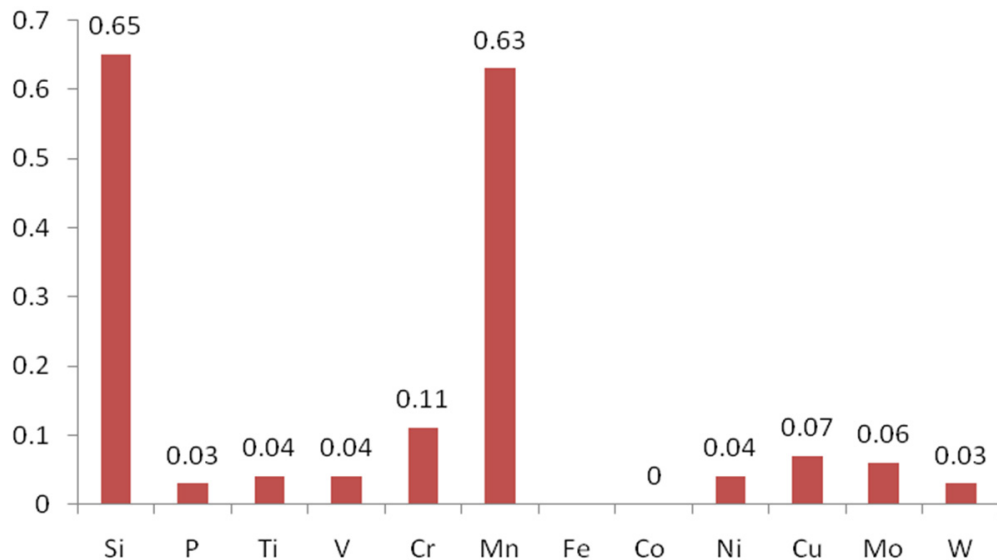

Figure 7: XRF analysis of point D, No Fe (98.30\%) included. 


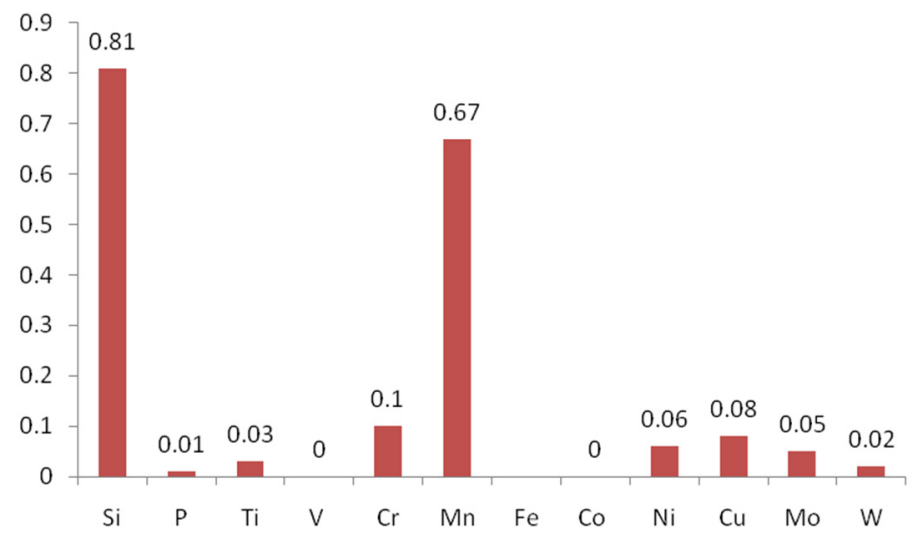

Figure 8: XRF analysis of point G, No Fe (98.09\%) included.

Fig. 9 shows the end views and the c-scan of the sample with implementation of colour coding Red for $0.00 \mathrm{~mm}$ and Blue for $10.00 \mathrm{~mm}$. Two cursors Red and Blue show the $x$-axis, $y$-axis location and the corresponding depths of the particular points on the sample.

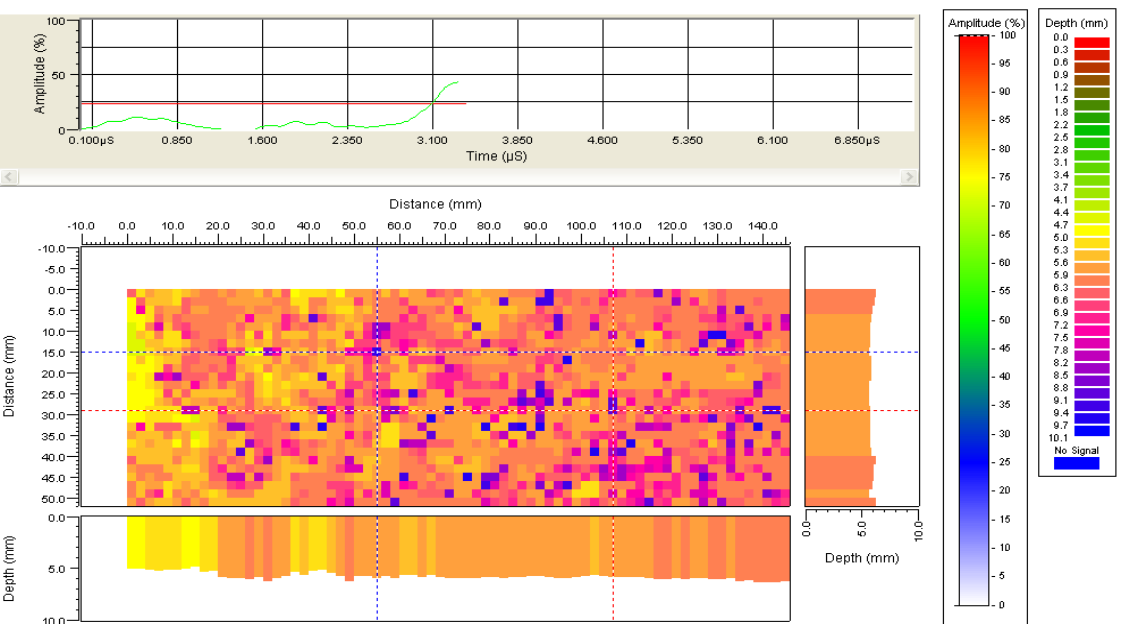

Figure 9: Pulse echo scan of M4A1.

A user defined area is taken for finding the maximum and minimum thicknesses starting at $2.00 \mathrm{~mm}$ on the $x$-axis, $2.00 \mathrm{~mm}$ on the $y$-axis in Fig. 10 and finishing at $172.00 \mathrm{~mm}$ on the $x$-axis and $66.00 \mathrm{~mm}$ at the $y$-axis in Fig. 11 respectively to avoid any distortion in signals at the edges. The scan detected maximum remaining thickness of $9.80 \mathrm{~mm}$ at horizontal position of $150.00 \mathrm{~mm}$ and vertical position of $26.00 \mathrm{~mm}$ with a drastic loss in material to a minimum of 
$4.60 \mathrm{~mm}$ at horizontal position of $28.00 \mathrm{~mm}$ and vertical position of $8.00 \mathrm{~mm}$. The maximum thickness of $9.80 \mathrm{~mm}$ is recorded at two different points. The second lowest depth is $4.70 \mathrm{~mm}$ and is detected at seven different positions; third lowest of $4.80 \mathrm{~mm}$ at six various points and the remaining thickness of $4.90 \mathrm{~mm}$ is recorded at four different points in the samples. The minimum remaining thickness of $4.60 \mathrm{~mm}$ is recorded at three different points.

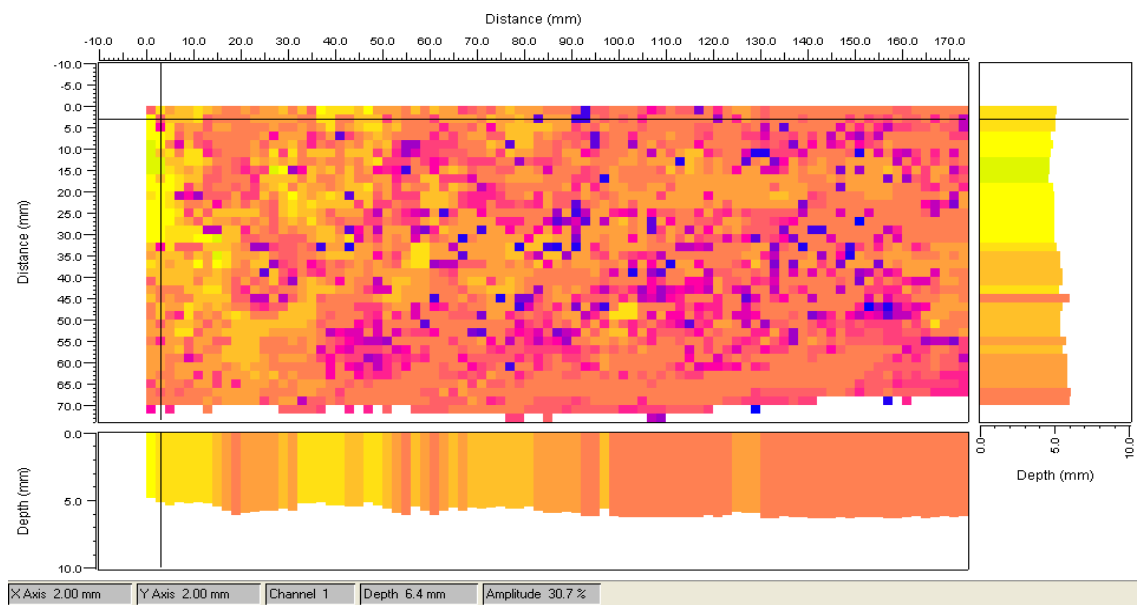

Figure 10: User defined area starting at $2.00 \mathrm{~mm}$ on $x$-axis and at $2.00 \mathrm{~mm}$ on $y$-axis.

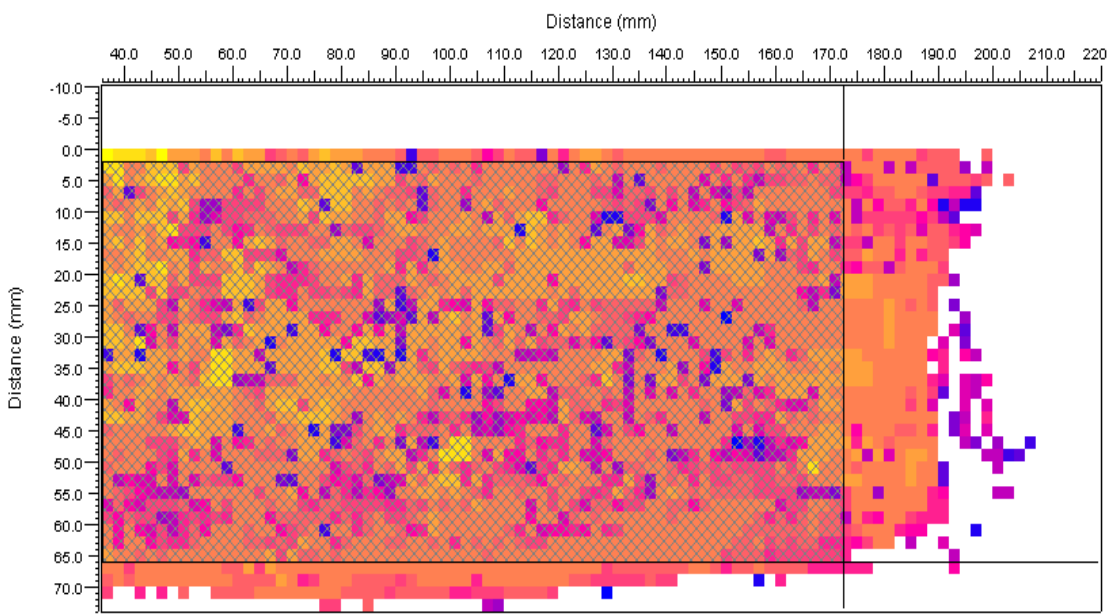

Figure 11: User defined area finishing at $174 \mathrm{~mm}$ on $x$-axis and at $66 \mathrm{~mm}$ on $y$-axis. 


\section{Discussion}

The modes of corrosion identified above can be retarded by using protective measures such as coatings and paint for uniform corrosion, application of lubrication and exclusion of air in the fretting corrosion, alleviating the stress in stress corrosion cracking, using same metal types in galvanic corrosion or applying insulation between two different metals.

The alloying elements such as $\mathrm{Mn}, \mathrm{Cr}, \mathrm{V}, \mathrm{W}$ and Mo identified though XRF are used as hardening agents to improve hardness, ductility and tensile strength [19]. Also Mo, Mn and P are used for the rust and corrosion prevention. Mo is used in high strength alloys and super alloys for strength and wear resistance [20].

Sherman M4A1 was designed by Lima Locomotive Works in the United States. At the time of manufacture, the armoured thickness range was kept between a maximum of $62.00 \mathrm{~mm}$ and a minimum of $12.00 \mathrm{~mm}$ [21, 22]. However it is not practical to follow any possible modification in the armour thickness and, for this reason, the highest thickness recorded in the scan is considered the maximum thickness. During the service life, exposure to extreme environments has led to the deterioration and material loss. The ultrasonic scan has shown a remarkable material loss of $5.20 \mathrm{~mm}$ between the maximum remaining thickness of $9.80 \mathrm{~mm}$ and the minimum remaining thickness of $4.60 \mathrm{~mm}$. Currently in the museum collection, the Sherman travels between two controlled and uncontrolled environments. Varying environments and the likelihood of failing protective measures, temperature fluctuations, humidity ratio variations, rain water and the extent of chemical reaction etc will influence the rate of corrosion and, in the controlled environment, corrosion residues may result in indoor atmospheric corrosion $[23,24]$.

\section{Conclusion}

The presented research work uses a conventional method of analysing corrosion through surveying vehicles in the museum environment; this is followed by novel methods of XRF for the elemental identification and ultrasonic scanning to measure and map corrosion. Further research will be conducted on corrosion modelling and life expectancy of large historic vehicles based upon the results from this work in order to maximise their longevity, durability and reliability.

\section{Acknowledgements}

The authors would like to thank Mark Nel, Mark Clark in AGR, Jon Previtt in West-Dean College and Mike Hayton in The Tank Museum Bovington for their in kind support during this research work. 


\section{References}

[1] Colavita, M., Service life and aging of military equipment. Corrosion: Environments and Industries, ASM Handbook, vol. 13C, eds. S.D. Cramer \& B.S. Covino, Jr., pp. 220-228, 2006.

[2] Agarwala, V.S., Corrosion in the military. Corrosion: Environments and Industries, ASM Handbook, vol. 13C, eds. S.D. Cramer \& B.S. Covino, Jr., pp. 126-135, 2006.

[3] Ahmad, Z., Principles of Corrosion Engineering and Corrosion Control, Ch. 2: Basic Concepts in Corrosion, Butterworth-Heinemann: Oxford, pp. 9-56, 2006.

[4] Handsy, I.C. \& Repp, J., Ground vehicle corrosion. Corrosion: Environments and Industries, ASM Handbook, vol. 13C, eds. S.D. Cramer \& B.S. Covino, Jr., pp. 148-150, 2006.

[5] Gudze, M.T. \& Melchers, R.E., Operational based corrosion analysis in naval ships. Corrosion Science, 50, pp. 3296-3307, 2008.

[6] Beckhoff, B., Handbook of Practical X-ray Fluorescence Analysis, Springer: Berlin, London, 2006.

[7] Grieken, R. v. \& Markowicz, A.A., Handbook of X-ray Spectrometry, 2nd ed., M. Dekker: New York, NY, 2002.

[8] Drury, J.C., Ultrasonic Flaw Detection for Technicians, 3rd ed. Silverwing Ltd.: Swansea, 2004.

[9] Baboian, R., Corrosion Tests and Standards: Application and Interpretation, ASTM: Philadelphia, PA, 1995.

[10] Uhlig, H.H. \& Revie, R.W., Corrosion and Corrosion Control: An Introduction to Corrosion Science and Engineering, 4th ed., WileyInterscience: Hoboken, NJ, 2008.

[11] Bill, R.C., The role of oxidation in the fretting wear process. Proc. of the Int. Conf. on Wear of Materials, San Francisco, CA, ASCE: New York, pp. 238-250, 1981.

[12] Neyman, A. \& Olszewski, O., Research on fretting wear dependence of hardness ratio and friction coefficient of fretted couple. Wear, 162-164, pp. 939-943, 1993.

[13] Procter, R.P.M., Omideyi, M.V.E., Newman, R.C. \& Zheng, W., Stresscorrosion cracking of C---Mn steels in methanol-ammonia environments-I. Effects of environmental and mechanical variables. Corrosion Science, 33, pp. 1009-1031, 1992.

[14] Newman, R.C., Stress corrosion cracking. Shreir's Corrosion, ed. J.A.R. Tony, Elsevier: Oxford, pp. 864-901, 2010.

[15] Hampel, C.A., The Encyclopedia of Electrochemistry, Reinhold; Chapman \& Hall, 1964.

[16] Hack, H.P., Galvanic corrosion. Shreir's Corrosion, ed. J.A.R. Tony, Elsevier: Oxford, pp. 828-856, 2010.

[17] Szklarska-Smialowska, Z., Pitting Corrosion of Metals, National Association of Corrosion Engineers: Houston, TX, 1986. 
[18] Baboian, R., Automotive Corrosion Tests and Standards, Society of Manufacturing Engineers, 1996.

[19] Ashby, M.F. \& Jones, D.R.H. Engineering Materials 2: An Introduction to Microstructures, Processing and Design, 3rd ed. Butterworth-Heinemann: Oxford, 2006.

[20] Schmidt, F.F., The Engineering Properties of Molybdenum and Molybdenum alloys, Defense Metals Information Center: Columbus, Ohio, 1963.

[21] Chamberlain, P. \& Ellis, C., British and American Tanks of World War II: The Complete Illustrated History of British, American, and Commonwealth Tanks, 1939-1945, Cassell \& Co.: London, New York, 2000.

[22] Jackson, R., Tanks and Armoured Fighting Vehicles, Parragon: Bath, 2007.

[23] Mendoza, A.R. \& Corvo, F., Outdoor and indoor atmospheric corrosion of non-ferrous metals. Corrosion Science, 42, pp. 1123-1147, 2000.

[24] Odnevall, I. \& Leygraf, C., The formation of $\mathrm{Zn} 4 \mathrm{Cl} 2(\mathrm{OH}) 4 \mathrm{SO} 45 \mathrm{H} 2 \mathrm{O}$ in an urban and an industrial atmosphere. Corrosion Science, 36, pp. 1551-1559, 1994. 